\title{
INTERTEKSTUALNA FUNKCJA CYTATU Z KSIĘGI OZEASZA W MATEUSZOWEJ EWANGELII DZIECIŃSTWA
}

Bibliści generalnie zgadzają się co do faktu, że Mateuszowa Ewangelia Dzieciństwa (Mt 1-2) zawiera pięć tzw. cytatów refleksyjnych. Są one wprowadzone za pomocą powtarzającej się z pewnymi modyfikacjami formuły, odwołującej się do wypełnienia się słów proroków $\mathrm{w}$ wydarzeniach relacjonowanych przez ewangelistę. $\mathrm{O}$ ile liczba tych cytatów nie stanowi dziś przedmiotu naukowej dyskusji, o tyle ich źródło i forma tekstualna, a także ich funkcja w Mateuszowym tekście, nie zostały jak dotąd dokładnie wyjaśnione.

\section{„Cytaty refleksyjne” w Mateuszowej Ewangelii Dzieciństwa}

Pierwszy z Mateuszowych „cytatów refleksyjnych” to cytat z Iz 7,14 LXX w Mt 1,23. Cytat ten został prawie dosłownie zaczerpnięty z Księgi Izajasza w wersji Septuaginty (idou hē parthenos en gastri hexei kai texetai hyion kai kales* to onoma autou Emmanouēl). ${ }^{1}$ Jedyną modyfikacją, dokonaną przez ewangelistę, jest zmiana formy liczby pojedynczej kaleseis (,nazwiesz” - Iz 7,14 LXX) na formę liczby mnogiej kalesousin („nazwą”- Mt 1,23c). Zmiana ta wynika najprawdopodobniej z dostosowania cytatu do nowego kontekstu narracyjnego w Ewangelii Mateuszowej. Ponieważ Józef miał tak naprawdę nadać dziecku imię Jezus (Mt 1,21.25), więc nazwanie

\footnotetext{
1 Por. M. T. P 1 o n e r, Die Schriften Israels als Auslegungshorizont der Jesusgeschichte: Eine narrative und intertextuelle Analyse von Mt 1-2, SBB 66, Stuttgart 2011, s. 259-265; G. M a i e r, Das Evangelium des Matthäus: Kapitel 1-14, HTA. NT, Witten-Giessen 2015, s. 84.
} 
dziecka Emmanuelem (Mt 1,23) musiało zostać przypisane innym postaciom narracji. ${ }^{2}$

Drugi ,cytat refleksyjny” to cytat z Mi 5,1.3 w Mt 2,6. Dokładnie rzecz biorąc, Mateuszowa forma cytatu (kai sy Bēthleem gē Iouda oudamōs elachistē ei en tois hēgemosin Iouda ek sou gar exeleusetai hēgoumenos hostis poimanei ton laon mou ton Israēl) wygląda na kontaminację tekstów Mi 5,1 (kai sy Bēthleem... ei... en *sin Iouda ek sou... exeleusetai... Israèl) i Mi 5,3 (kai... poimanei) z 2Sm 5,2 LXX (kai... sy... poimanei* ton laon mou ton Israèl + kai sy... hēgoumeno*). ${ }^{3}$ Co ciekawe, grecki tekst Mi 5,1.3, znaleziony wśród pism znad Morza Martwego (8HevXIIgr 8.32-42) generalnie zgadza się z tekstem Septuaginty, a nie z tekstem Mateusza. Hipoteza, że Mateusz wykorzystał inną, krążącą wówczas w Palestynie, grecką wersję Mt 5,1.3 jest zatem trudna do udowodnienia.

Trzeci ,cytat refleksyjny” to omawiany szerzej w niniejszym artykule cytat z Oz 11,1 w Mt 2,15.

Czwarty „cytat refleksyjny” to cytat z Jr 31[38],15 LXX w Mt 2,18. Mateuszowa wersja cytatu (phōnē en Rama è kousthē klauthmos kai odyrmos polys Rachēl klaiousa ta tekna autēs kai ouk èthelen paraklēthēnai hoti ouk eisin) częściowo zgadza się z tekstem Księgi Jeremiasza w wersji Septuaginty (phōnē en Rama ēkousthē...

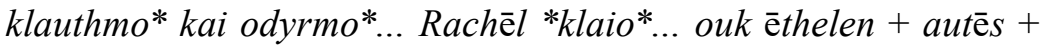

2 Por. A. K o w a l c z y k, The Influence of Typology and Texts of the Old Testament on the Redaction of Matthew's Gospel, Pelplin 2008, s. 165; G. C 1 a u d e 1, Joseph, figure du lecteur modèle du premier évangile, w: D. S e n i o r (red.), The Gospel of Matthew at the Crossroads of Early Christianity, BETL 243, Leuven-Paris-Walpole, Mass. 2011, s. 346-347.

3 Por. A. D e stro, M. P e s ce, The Cultural Structure of the Infancy Narrative in the Gospel of Matthew, w: C. C 1 i v a z i in. (red.), Infancy Gospels: Stories and Identities, WUNT 281, Tübingen 2011, s. 102-103; M. M a y o r d o m o, Matthew 1-2 and the Problem of Intertextuality, w: tamże, s. 275-276; G. M a i e r, Matthäus: Kapitel 1-14, s. 101-103. 
hoti ouk eisin), a częściowo odzwierciedla tekst hebrajski („opłakuje swe dzieci”, ,,pocieszyć”). ${ }^{4}$

Wreszcie piąty „cytat refleksyjny” to cytat z Iz 11,1 w Mt 2,23. Źródło tego cytatu nie jest jasne, gdyż żaden z proroków, a tym bardziej - jak sugeruje św. Mateusz - kilku proroków jednocześnie, nie podaje tekstu ,nazwany będzie Nazorejczykiem” (Nazōraios klēthēsetai: Mt 2,23). Można się jednak domyślać, że źródłem Mateuszowego cytatu był hebrajski tekst mesjańskiego proroctwa Iz 11,1, zawierającego słowo $n \overline{\mathrm{e}} c e r$ (,odrośl”). ${ }^{5}$ Mateusz poszedłby tu za przykładem św. Marka, który, używając słowa „Nazarejczyk”, również aluzyjnie wykorzystał hebrajski tekst Iz 11,1 jako profetycznie odnoszący się do pochodzenia Jezusa z rodu Dawida (Mk 10,47: „Nazarejczyk” - ,syn Dawida”; por. także Mk 1,9). ${ }^{6}$

Ciekawy jest przy tym fakt, że nie-Markowa forma przymiotnika Nazōraios (Mt 2,23) występuje w Ewangelii Mateuszowej dwa razy (Mt 2,23; 26,7), natomiast Łukasz użył jej w swej Ewangelii tylko raz (Łk 18,37) i aż siedem razy w Dziejach Apostolskich (Dz 2,22; $3,6 ; 4,10 ; 6,14 ; 22,8 ; 24,5 ; 26,9)$. Można na tej podstawie stwierdzić, że ta forma przymiotnika jest charakterystycznie Łukaszowa, ${ }^{7}$ a zatem najprawdopodobniej została zapożyczona przez św. Mateusza z dwudzieła św. Łukasza.

4 Por. M. T. Plo n e r, Schriften, s. 299-300; G. C 1 a u d e 1, Joseph, s. 366-368; E. E.-C. P a r k, Rachel's Cry for Her Children: Matthew's Treatment of the Infanticide by Herod, CBQ 75/2013, s. 480-481.

5 Por. A. W u c h e r p fe $\mathrm{n} n \mathrm{ig}$, Josef der Gerechte: Eine exegetische Untersuchung zu Mt 1-2, HBS 55, Freiburg i in. 2008, s. 164-167.

6 Por. B. A d a m c z e w s k i, The Gospel of Mark: A Hypertextual Commentary, EST 8, Frankfurt am Main i in. 2014, s. 38-39, 138.

7 Por. A. De na ux, R. Corst je n s, H. Mardaga, The Vocabulary of Luke: An Alphabetical Presentation and a Survey of Characteristic and Noteworthy Words and Word Groups in Luke's Gospel, BTS 10, Leuven-Paris-Walpole, Mass. 2009, s. 410-411. 


\section{Forma cytatu z Oz 11,1 w Mt 2,15}

Tekst Mt 2,15 można dosłownie przetłumaczyć następująco: „I był tam aż do skończenia [życia] Heroda, aby wypełniło się to, co wypowiedziane zostało przez Pana poprzez proroka, mówiącego: «Z Egiptu zawołałem Syna mego»"'.

Prorocki cytat: „Z Egiptu zawołałem Syna mego” ewidentnie pochodzi z Księgi Ozeasza (Oz 11,1). Problemem jest jednak jego forma. Czy pochodzi on z Oz 11,1 w wersji Septuaginty, czy też z tekstu hebrajskiego?

Mateusz ewidentnie znał i wykorzystywał grecką wersję Biblii żydowskiej. Dowodzi tego chociażby prawie dosłowny, długi cytat z Iz 7,14 LXX w pierwszym ,cytacie refleksyjnym” (Mt 1,23). Innym przykładem może być również długi cytat z Pwt 8,3 LXX w Mt 4,4.

W przypadku cytatu z Oz 11,1 w Mt 2,15 jego początek (ex Aigyptou) dokładnie zgadza się z Oz 11,1 w wersji Septuaginty, co może świadczyć o świadomym cytowaniu tej wersji, a nie własnym tłumaczeniu z hebrajskiego, gdyż Mateusz w takich frazach zwykle używał przyimka apo. ${ }^{8}$ Dalej jednak występują wyraźne różnice w stosunku do tej greckiej wersji Biblii żydowskiej.

Pierwszą z tych różnic jest zmiana czasownika metakaleō (,,przywołać skądś” - Oz 11,1 LXX) na kaleō (,zawołać” - Mt 2,15). Mateuszowy czasownik kaleō znaczeniowo odpowiada hebrajskiemu $q \bar{a} r \bar{a}$, który użyty został w Oz 11,1 (w tekście maso reckim), a więc w tym przypadku można postawić hipotezę, że Mateusz posłużył się hebrajską wersją tekstu Ozeasza. Trudno jednakże jednoznacznie uznać wersję Mateuszową za korektę tłumaczenia Septuaginty na podstawie tekstu hebrajskiego, gdyż - przynajmniej dla tłumacza Septuaginty - także metakaleō był semantycznym odpowiednikiem hebrajskiego czasownika qārā', (Oz 11,1-2). Niestety, wśród pism znad Morza Martwego nie zachowało się greckie tłumaczenie Oz 11,1

8 Por. S. M o y i s e, Matthew's Bible in the Infancy Narrative, w: B. J. K o e t, S. Moy i s e, J. Verh e y d e n (red.), The Scriptures of Israel in Jewish and Christian Tradition. FS M. J. J. Menken, NovTSup 148, Leiden-Boston 2013, s. 18-19. 
(fragmentarycznie zachowany zwój 8HevXIIgr nie zawiera tego tekstu), nie wiemy więc, czy w czasach św. Mateusza istniały jakieś inne próby przełożenia hebrajskiego tekstu Oz 11,1 na język grecki.

Druga różnica polega na zmianie rzeczownika tekna (,dzieci”Oz 11,1 LXX) na hyios (,syn” - Mt 2,15). W tym przypadku trudno stwierdzić, czy Mateusz posłużył się hebrajską wersją Oz 11,1. W niewokalizowanym tekście hebrajskim sufigowana forma bny $(\mathrm{Oz} 11,1$ TM) może być bowiem formą zarówno liczby pojedynczej („,mój syn” - por. np. Rdz 21,10), jak i liczby mnogiej (,moi synowie” por. np. Rdz 31,43), zaś sam rzeczownik bn może oznaczać zarówno syna (por. np. Rdz 4,17), jak i ogólnie dziecko (por. np. $R d z$ 3,16). Tłumacz Septuaginty prawdopodobnie oparł swój przekład (tekna„dzieci” - Oz 11,1 LXX) na tej wieloznaczności hebrajskiego słowa bny, zwłaszcza że dalsza część tekstu $(\mathrm{Oz} 11,2)$ sformułowana jest w liczbie mnogiej. Wersja Mateusza (,syn”- Mt 2,15) wygląda na znaczeniowo bliższą tekstowi masoreckiemu Oz 11,1, ale w tym przypadku trudno jednoznacznie stwierdzić, że jest ona korektą tłumaczenia Septuaginty, opartą na dość wieloznacznym tekście hebrajskim.

Trzecią różnicą jest zmiana zaimka w 3. osobie (autou - ,jego" Oz 11,1 LXX) na zaimek w 1. osobie (mou - „mojego” - Mt 2,15). W tym przypadku tekst Mateusza jest wyraźnie bliższy tekstowi hebrajskiemu (sufiks zaimkowy 1. osoby -y: Oz 11,1 TM) niż tekstowi Septuaginty.

Ogólnie rzecz biorąc, forma cytatu z Oz 11,1 w Mt 2,15 zbliżona jest bardziej do tekstu hebrajskiego oraz do przekładu Akwili niż do tłumaczenia Septuaginty. ${ }^{9}$ Trudno jednak wykazać, że Mateusz skorygował tekst Septuaginty, opierając się na wieloznacznym tekście hebrajskim. Poza tym pozostałe Mateuszowe cytaty z Księgi Ozeasza wiernie oddają wersję Septuaginty (eleos thelō kai ou thysian: Oz 6,6 LXX w Mt 9,13; 12,7). Uprawnione jest zatem szukanie jeszcze innych wyjaśnień pochodzenia dość nietypowej formy greckiego cytatu z Oz 11,1 w Mt 2,15.

9 Por. A. W u c he r p fen n ig, Josefder Gerechte, s. 146; M. T. P l o n e r, Schriften, s. 293. 


\section{Nowe podejście: relacje synoptyczne}

W celu wyjaśnienia problemu formy i funkcji cytatu z Oz 11,1 w Mt 2,15 pomocne może okazać się przeanalizowanie pozornie niezwiązanego z tym problemem zagadnienia, a mianowicie kwestii relacji synoptycznych, zachodzących między Ewangeliami. Powszechnie wiadomo, że większość biblistów opowiada się dziś za teorią istnienia ,źródła Q”, generalnie pojmowanego jako zbiór tekstów nieobecnych w Ewangelii Markowej, a wykorzystanych przez Mateusza i Łukasza. Istnieją jednak obecnie przynajmniej dwie poważne hipotezy alternatywne, mianowicie Łukaszowego wykorzystania Marka i Mateusza (tzw. hipoteza Farrera-Gouldera) oraz Mateuszowego wykorzystania Marka i Łukasza (tzw. Matthean Posteriority Hypothesis). ${ }^{10}$ Tym alternatywnym hipotezom poświęcone zostały dwie obszerne, wydane w ubiegłym roku monografie.

Pierwsza z tych monografii to praca zbiorowa Marcan Priority without Q: Explorations in the Farrer Hypothesis. ${ }^{11}$ We wstępie do tej książki jeden z jej redaktorów, J. C. Poirier, słusznie stwierdza, że hipotezy alternatywne względem teorii ,źródła Q” zyskują dziś na popularności m.in. dlatego, że coraz większe grono badaczy postrzega ewangelistów jako kreatywnych autorów, a nie tylko kompilatorów wcześniejszego materiału, oraz przesuwa daty powstania Ewangelii na lata późniejsze, nawet na II w., po zebraniu kolekcji listów Pawłowych. ${ }^{12}$

Druga monografia to książka Matthean Posteriority: An Exploration of Matthew's Use of Mark and Luke as a Solution to the Synoptic Problem. ${ }^{13}$ Jej autor, Robert K. MacEwen, prezentuje w niej

10 Por. U. S c h n e 11 e, Einleitung in das Neue Testament, UTB 1830, Göttingen $2013^{8}$, s. 237-241.

11 J. C. P o irier, J. Peters on (red.), Marcan Priority without $Q$ : Explorations in the Farrer Hypothesis, LNTS 455, London-New York 2015.

12 J. C. P o i r i e r, Introduction: Why the Farrer Hypothesis? Why Now? $\mathrm{w}$ tamże, s. 2-6, 11-13.

13 R. K. M a c Ew e n, Matthean Posteriority: An Exploration of Matthew's Use of Mark and Luke as a Solution to the Synoptic Problem, LNTS 501, London-New York 2015. 
lingwistyczne i literackie argumenty za hipotezą Mateuszowego wykorzystania Marka i Łukasza, które czynią ją bardziej prawdopodobną niż inne rozwiązania problemu synoptycznego. Wyjaśnia także, dlaczego lingwistyczne i literackie argumenty przeciw tej hipotezie są w istocie błędne lub mało znaczące.

Z pewnością należy docenić wartość obu tych monografii jako prezentujących hipotezy alternatywne względem dominującej w badaniach nad problemem synoptycznym teorii ,źródła Q”. Jednakże słabością tych prac, podobnie jak większości publikacji poświęconych problemowi synoptycznemu, jest izolowanie Ewangelii Łukaszowej od drugiej części Łukaszowego dwudzieła, a mianowicie od Dziejów Apostolskich. W istocie trudno sobie wyobrazić, by dla relacji literackich zachodzących między Ewangeliami synoptycznymi istotna była tylko Łukaszowa Ewangelia, bez drugiej części jego narracji. Fakt ten jest istotny zwłaszcza dla hipotezy Mateuszowego wykorzystania Marka i Łukasza. Jeżeli, jak argumentuje Robert K. MacEwen i inni, Mateusz korzystał z Łukaszowej Ewangelii, to czy można sobie wyobrazić całkowity brak zainteresowania z jego strony Dziejami Apostolskimi? Taka ewentualność wydaje się bardzo mało prawdopodobna. Powstaje jednak problem: Jeżeli Mateusz literacko korzystał także z Dziejów Apostolskich, to w jaki konkretnie sposób to czynił?

W jednej z moich wcześniejszych publikacji zasugerowałem, że Mateusz korzystał z Dziejów Apostolskich w sposób literacko kreatywny, lecz jednocześnie ściśle sekwencyjny, tzn. z zachowaniem porządku idei, motywów literackich itp. z Dziejów Apostolskich. Na ówczesnym etapie badań w sposób dość prowizoryczny zasugerowałem, że w Ewangelii według św. Mateusza da się wyodrębnić 22 sekcje, które tematycznie odpowiadają analogicznym sekcjom z Dziejów Apostolskich. ${ }^{14}$ Propozycja ta była ewidentnie niedoskonała, gdyż oparta była wyłącznie na pewnym podobieństwie tematycznym, bez uwzględnienia powiązań lingwistycznych. Poza tym, w analizie Mateuszowej Ewangelii Dzieciństwa panowało pewne zamieszanie, gdyż według ówczesnej propozycji sekcji

14 B. A d a m c z e w s k i, Q or not Q? The So-Called Triple, Double, and Single Traditions in the Synoptic Gospels, Frankfurt am Main i in. 2010, s. 428-430. 
Dz 1,1 - 8,3 odpowiadałyby odizolowane od siebie nawzajem fragmenty Mt 1,1 - 2,12; 2,16-18, zaś kolejnej sekcji Dz 8,25-39 odpowiadałby znajdujący się między nimi fragment Mt 2,13-15. ${ }^{15}$

Uwzględnienie szczegółowych powiązań lingwistycznych, a nie tylko ogólnych podobieństw tematycznych, prowadzi jednak do wniosku, że fragment Mt 2,13-15 jest w istocie efektem przetworzenia sekcji Dz 3, które również zostało zorganizowane ściśle sekwencyjnie, w sposób dużo bardziej szczegółowy, niż to pierwotnie dało się dostrzec.

\section{Mt 2,13-15 efektem sekwencyjnego przetworzenia Dz 3}

Fragment Mt 2,13-15, opisujący ucieczkę Józefa z rodziną do Egiptu, nie ma paralel w innych Ewangeliach. Zazwyczaj taktowany jest on więc przez biblistów jako materiał własny św. Mateusza, być może zaczerpnięty przez niego z jakiegoś nieznanego nam źródła. Dość oczywiste jest wykorzystanie w tym fragmencie różnych motywów starotestamentalnych (pojawienie się anioła Pana, udanie się z ziemi Izraela do Egiptu, zły król usiłujący zgładzić Bożego wybrańca itp.). Wyjaśnienie sekwencji wykorzystania tych motywów oraz ich ewentualnego związku z Dziejami Apostolskimi wymaga jednak bardziej szczegółowych analiz intertekstualnych.

Otwierający analizowany fragment obraz, w którym oto (idou) anioł (aggelos) pojawia się (phainō) pobożnemu Izraelicie (Mt 2,13ab), jest wynikiem przetworzenia Łukaszowego obrazu pobożnych apostołów, przychodzących do świątyni w godzinie modlitwy, o godzinie dziewiątej (Dz 3,1). W Dziejach Apostolskich motyw godziny dziewiątej, jako godziny modlitwy (Dz 3,1), skorelowany jest z motywem godziny dziewiątej jako czasu, w którym oto (idou) anioł (aggelos) jest jawnie (phanerōs) widziany przez pobożnego człowieka (Dz 10,3.30). Mateusz powiązał te tematycznie skorelowane Łukaszowe motywy modlitwy pobożnych apostołów o godzinie dziewiątej (Dz 3,1) oraz jawnego ukazania się anioła Bożego pobożnemu

15 Tamże, s. 428-429. 
człowiekowi o tej właśnie godzinie (Dz 10,3.30), uzyskując w ten sposób obraz, w którym oto anioł pojawia się pobożnemu Izraelicie (Mt 2,13ab). Dodatkowo Mateusz wzbogacił ten obraz w Mt 2,13b o motywy starotestamentalne: pobożnego Izraelity otrzymującego anielskie (aggel*) objawienie we śnie (Dn 8,2.19; 9:21 LXX) oraz Józefa (Iōsēph) mającego szczególne sny (Rdz 37,5-20).

Kolejny motyw nakazania (legō) Józefowi, by wstał (egeirōMt 2,13cd), jest właściwie zbędny z narracyjnego punktu widzenia. Bezpośrednio poprzedzający, tematycznie zbliżony motyw polecenia we śnie, by inną drogą udać się do ojczyzny (Mt 2,12), nie zawiera bowiem nakazu powstania. $Z$ punktu widzenia intertekstualnego motyw ten lingwistycznie i tematycznie odzwierciedla jednak kolejny motyw Łukaszowy, a mianowicie motyw nakazania (legō) chromemu człowiekowi, by wstał (egeirō), tak że ten rzeczywiście wstał (egeirō: Dz 3,2-7). To intertekstualne przepracowanie Łukaszowego tekstu Dz 3,2-7 w Mt 2,13cd dodatkowo potwierdza, że dłuższa lekcja egeire kai w Dz 3,6 $6^{16}$ jest lekcją pierwotną.

Następujący dalej obraz Józefa jako biorącego (paralambanō: por. Mt 1,21.24) dwoje najważniejszych dla niego osób, z Dzieckiem na pierwszym miejscu (Mt 2,13e; inaczej niż w 1,21.24), tematycznie odzwierciedla następujący dalej Łukaszowy obraz uzdrowionego człowieka jako stale trzymającego się dwóch najważniejszych apostołów, z Piotrem na pierwszym miejscu (Dz 3,8-11).

Kolejny, biblijny motyw drogi Józefa, niczym jego patriarchalnego imiennika, z Dzieckiem ( paid*$^{*}$ ) do Egiptu (eis Aigypton), a następnie pozostania tam przez długi czas (Mt 2,13f-h), jest efektem przetworzenia dwóch kolejnych, wykorzystanych przez Łukasza motywów: Boga biblijnych patriarchów oraz Boga, który wsławił (doxa*) swego świętego i sprawiedliwego Sługę/Dziecko (pais), który został wydany (*didomi) przez Żydów poganom (Dz 3,13-14). Mateusz tematycznie powiązał ze sobą te dwa skorelowane Łukaszowe motywy i postawił pytanie: Kiedy w historii biblijnych patriarchów Bóg wsławił swego

16 Zob. B. M. M e t z g e r, A Textual Commentary on the Greek New Testament, Stuttgart $1998^{2}$, s. 267. 
świętego i sprawiedliwego Sługę/Dziecko, który został wydany przez Żydów poganom (por. Dz 3,13-14)? Odpowiedzią jest biblijna historia patriarchy Józefa, który został wydany jako dziecko przez Judę i jego braci do Egiptu (Rdz 37,26-28.30 LXX), którego Bóg tam wsławił ( $R d z$ 45,13 LXX) i który pozostał tam przez długi czas ( $R d z$ 39-50). $\mathrm{Z}$ tego powodu skorelowane Łukaszowe motywy Boga biblijnych patriarchów oraz Boga, który wsławił swego świętego i sprawiedliwego Sługę/Dziecko, który został wydany przez Żydów poganom (Dz 3,13-14), mogły być wspólnie przedstawione przez Mateusza w biblijnych kategoriach jako quasi-patriarchalna droga nowego Józefa do Egiptu i jego długi pobyt w tym kraju (Mt 2,13f-h).

Następujący dalej motyw decyzji Heroda, by zgładzić Jezusa (Mt 2,13i-k), tematycznie odzwierciedla następujący dalej Łukaszowy motyw decyzji Żydów, by zabić Jezusa (Dz 3,15). Kolejne stwierdzenie, że Józef, powstawszy, wziął Dziecko i Jego matkę (egertheis parelaben to paidion kai tēn mētera autou - Mt 2,14ab) narracyjnie wyraża ideę wypełnienia danego wcześniej Józefowi polecenia, by powstawszy, wziął Dziecko i Jego matkę (egertheis paralabe to paidion kai tēn mètera autou - Mt 2,13de). W ten sposób, wykorzystując Markowy motyw powstania (egeirō) i pójścia jako wiernego wypełnienia nakazu Jezusa (por. Mk 2,11-12), Mateusz zobrazował ideę wiary i jej efektów. Tematycznie i lingwistycznie zilustrował tym samym kolejne Łukaszowe stwierdzenie, że wiara w Jezusa umocniła człowieka i dała mu całkowite zdrowie (Dz 3,16), tak że mógł on powstać (egeirō) i chodzić (por. Dz 3,6-8).

Zastosowany dalej motyw nocy jako czasu ucieczki do Egiptu (Mt 2,14b-15a) jest narracyjnie właściwie zbędny. W poprzednim zdaniu stwierdzono bowiem, że Herod dopiero ma zamiar szukać Dziecka (Mt 2,13i-k), a nie że już teraz - w nocy - Go szuka (por. Mt 2,16). Noc ma tu zatem charakter symboliczny, obrazując wrogi względem Jezusa stan Judei pod panowaniem Heroda (Mt 2,14b-15a; por. Dz 9,25; 17,10; 23,23.31). ${ }^{17}$ Za pomocą tego symbolicznego obrazu

17 Por. J. K e n n e d y, The Recapitulation of Israel: Use of Israel's History in Matthew 1:1 - 4:11, Tübingen 2008, s. 138-139; G. C 1 a u d e 1, Joseph, s. 363. 
Judei pozostającej w ciemności pod władzą Heroda Mateusz zobrazował zastosowany dalej przez Łukasza motyw braku poznania ze strony Żydów i ich władców, co doprowadziło ich do zabicia Jezusa (Dz 3,17).

Kolejny motyw wypełnienia (plēroō) tego, co wypowiedziane zostało przez Pana przez (dia) proroka (prophètēs - Mt 2,15b-d), jest dość wierną lingwistycznie i tematycznie przeróbką kolejnego Łukaszowego motywu wypełnienia (plēroō) tego, co zapowiedziane zostało przez Boga przez (dia) proroków (prophètēs - Dz 3,18.21).

W następnym, prorockim motywie przyjścia z Egiptu (Mt 2,15e) cytat z Ozeasza został tak zmieniony, że użyty w Septuagincie czasownik metakaleō (,przywołać skądś” - Oz 11,1 LXX) został zastąpiony czasownikiem kaleō (,zawołać” - Mt 2,15). Czasownik ten, w kontekście wyjścia z Egiptu, użyty został w Septuagincie w opisie powołania Mojżesza przez Pana (kaleō- Wj 3,4 LXX). Lingwistyczne powiązanie tych dwóch tekstów w Mateuszowym obrazie ,zawołania” Jezusa przez Pana z Egiptu (Mt 2,15e) obrazuje więc ideę zapowiedzianego przez proroka przyjścia Jezusa na sposób Mojżesza, który został ,zawołany” przez Pana w Egipcie. Ta idea tematycznie ilustruje zaś następny Łukaszowy, prorocki motyw wzbudzenia Mesjasza w sposób przypominający Mojżesza („Pan wzbudzi /.../ jak mnie" - Dz 3,22-23), co zostało zapowiedziane także przez późniejszych proroków (Dz 3,24).

Końcowy obraz Jezusa jako Bożego Syna (hyios - Mt 2,15e) osiągnięty został przez zastąpienie użytego w Septuagincie rzeczownika tekna (,dzieci” - Oz 11,1 LXX) rzeczownikiem hyios (,syn” Mt 2,15e). W ten sposób Mateusz uczynił lingwistyczną i tematyczną aluzję do końcowych Łukaszowych motywów synów (hyios) Bożego przymierza (Dz 3,25) i Jezusa jako Bożego Sługi/Dziecka (Dz 3,26).

\section{Forma i intertekstualna funkcja cytatu z Oz 11,1 w Mt 2,15}

Zaprezentowana powyżej dziesięcioelementowa sekwencja przetworzenia kolejnych motywów i idei z Lukaszowego tekstu Dz 3 w Mateuszowym tekście Mt 2,13-15 wyjaśnia przede wszystkim 
formę cytatu z Oz 11,1 w Mt 2,15. Jeżeli przedstawiona hipoteza intertekstualnego przepracowania Dz 3 w Mt 2,13-15 jest prawdziwa, to różnice w formie cytatu z Oz 11,1 w Mt 2,15 w stosunku do wersji Septuaginty (Oz 11,1 LXX) nie wynikły ani z własnego, niezależnego tłumaczenia tekstu hebrajskiego na grekę przez św. Mateusza (jak czynili to później Akwila, Symmach i Teodocjon), ani też z wykorzystania przez św. Mateusza jakiegoś nieznanego nam greckiego przekładu Księgi Ozeasza. Różnice w Mt 2,15 w stosunku do Oz 11,1 LXX wynikają przede wszystkim z zamiaru dostosowania tekstu Oz 11,1 LXX do idei i sformułowań, zawartych w Dz 3,22-26.

Zmiana czasownika metakaleō (Oz 11,1 LXX) na kaleō (Mt 2,15) wynika z lingwistycznego powiązania tekstu Oz 11,1 LXX z t ekstem Wj 3,4 LXX, który opisuje powołanie (kaleō) Mojżesza w Egipcie, a w ten sposób pośrednio ilustruje Łukaszową ideę przyjścia Jezusa jako nowego Mojżesza (Dz 3,22-24). Natomiast następująca dalej zmiana rzeczownika tekna (Oz 11,1 LXX) na hyios (Mt 2,15) tworzy lingwistyczną aluzję do następujących dalej Łukaszowych motywów synów (hyios) przymierza oraz Jezusa będącego w szczególnej relacji z Bogiem (Dz 3,25-26).

Istotniejsza od nietypowej formy cytatu z Oz 11,1 w Mt 2,15 jest jednak jego intertekstualna funkcja. Sama literacka formuła wprowadzenia prorockiego „cytatu refleksyjnego” (Mt 2,15b-d) w wyjątkowo wierny lingwistycznie i tematycznie sposób odzwierciedla Łukaszowy motyw wypełnienia w Jezusie tego, co Bóg zapowiedział przez proroków (Dz 3,18.21). Jak się okazuje, przynajmniej ten ,cytat refleksyjny" nie jest więc tworem charakterystycznie Mateuszowym, ale jest efektem intertekstualnego przetworzenia podobnych cytatów i teologicznych motywów z dzieła Łukaszowego.

Także nieco zaskakujące użycie w Mt 2,15 cytatu właśnie z Oz 11,1, który nie został wykorzystany w żadnym innym miejscu Nowego Testamentu, ma na celu stworzenie obrazu Jezusa jako zapowiedzianego przez proroków nowego Mojżesza, podobnie jak on wezwanego przez Pana w Egipcie (por. Wj 3,4). W ten sposób intertekstualnie zilustrowana została kolejna Łukaszowa idea Jezusa jako nowego Proroka na wzór Mojżesza (Dz 3,22-24). 
Wreszcie podkreślenie za pomocą zmodyfikowanego cytatu z Oz 11,1 LXX, że Jezus jest Synem, a nie jedynie dzieckiem Bożym (Mt 2,15), tworzy intertekstualną aluzję do końcowych Łukaszowych motywów bycia w szczególnej relacji z Bogiem (Dz 3,25-26). Celowo „,niska” chrystologia tej sekcji Dziejów Apostolskich, etopeicznie obrazująca chrystologię pierwotnej judeochrześcijańskiej wspólnoty jerozolimskiej (Jezus jako Sługa Boży: Dz 3-4), została jednak zmieniona przez Mateusza na „wysoką" chrystologię Jezusa jako Syna Bożego (Mt 2,15). Jak widać, intertekstualne wykorzystanie Łukaszowego dzieła nie oznaczało dla Mateusza prostego przejmowania wszystkich Łukaszowych idei teologicznych.

$$
* * *
$$

Szczegółowa analiza intertekstualnych powiązań Mt 2,13-15 z Łukaszowym tekstem Dz 3 prowadzi do wniosku, że fragment Mt 2,13-15 jest efektem ściśle sekwencyjnego, a jednocześnie wysoce kreatywnego przetworzenia kolejnych idei, motywów i słów kluczowych, występujących w Dz 3. Na tej podstawie da się stwierdzić, że kończący fragment Mt 2,13-15 cytat z Oz 11,1 LXX został użyty i umyślnie zmodyfikowany przez Mateusza w celu intertekstualnego zilustrowania Łukaszowych idei, zawartych w końcowej części sekcji Dz 3: wypełnienia w Jezusie tego, co Bóg zapowiedział przez proroków (Dz 3,18.21), Jezusa jako nowego Proroka na wzór Mojżesza (Dz 3,22-24) oraz Jezusa będącego w szczególnej relacji z Bogiem (Dz 3,25-26).

ks. Bartosz ADAMCZEWSKI

Słowa kluczowe: analiza intertekstualna, cytaty, Księga Ozeasza, Ewangelia Dzieciństwa, Dzieje Apostolskie

Keywords: Intertextual analysis, quotations, The Book of Hosea, Infancy Narratives, The Acts of the Apostles 
The Intertextual Function of the Quotation from the Book of Hosea in the Matthean Infancy Narrative

\section{Summary}

A detailed intertextual analysis of the links between Mt 2:13-15 and the Lucan text of Acts 3 leads to the conclusion that the text of Mt 2:13-15 is an outcome of a strictly sequential, but on the other hand a highly creative reworking of the ideas, motifs, and key words which occur in Acts 3. Therefore, it can be argued that the quotation from LXX Hos 11:1, which concludes the text of Mt 2:13-15, was used and consciously modified by Matthew in order to illustrate intertextually the Lucan ideas which are contained in the concluding part of Acts 3: the fulfilment in Jesus of that which God foretold by the prophets (Acts 3:18,21), Jesus as the new Prophet like Moses (Acts 3:22-24), and Jesus being in a particular relationship with God (Acts 3:25-26). 